DOI: 10.14526/2070-4798-2019-14-2-53-59

\title{
Criteria of the load dosing during physical culture and health improving lesson, organized by means of "Historical Terrainkur"
}

\author{
Elina V. Bulanova*, Maria O. Kuzmina, Vladimir Sh. Kakaliya \\ Tver State Medical University \\ Tver, Russia \\ ORCID: oooo-0oo3-2336-3835, elina.bulanova@mail.ru \\ ORCID: 0000-0002-1685-0443, kuzminamaria200o@yandex.ru \\ ORCID: 000o-0002-9899-6592, vladimirkakalia@mail.ru
}

\begin{abstract}
Observing modern tendencies in motor activity among students we came to the conclusion that boys and girls deny traditional forms of physical culture lessons and choose the directions. They mainly correspond with students' style of life, social and psychological status, morpho-functional abilities. It conditions pedagogical objective to modernize physical upbringing system at a higher educational establishment and create new forms of lessons organization with students. Materials. The research work presents the results of physical culture and health improving lessons (organized by means of "Historical Terrainkur") influence on medical department students' functional state and health. We held 4 experimental lessons. They were differentiated according to the parameters of the load, in order to create the criteria of the load dosing on the routes of "Historical Terrainkur". 132 students took part in the experiment. They all belonged to a special group of health. Research methods. Pedagogical experiment, a survey according to complains of health state among students, testing students' health state according to points, sociological survey, statistical data handling, research results analysis and summarizing. Results. It is necessary to dose the load on "Historical Terrainkur" routes according to the following: speed of movement - the quantity of steps within one minute, the duration of the route - general time of terrainkur. Conclusion. Physical culture and health improving lessons, organized by means of "Historical Terrainkur", were highly appreciated by students of a special medical department. They can be recommended as a new form of physical culture lessons organization for students.
\end{abstract}

Keywords: students, physical culture special medical group, dosed walking.

For citations: Elina V. Bulanova, Maria O. Kuzmina, Vladimir Sh. Kakaliya. Criteria of the load dosing during physical culture and health improving lesson, organized by means of "Historical Terrainkur". The Russian Journal of Physical Education and Sport. 2019; 14(2): 46-51. DOI 10.14526/2070-4798-2019-142-53-59.

According to a thorough medical check-

As a rule, during physical culture lessons up among students from Tver State Medical University 2016-2018, 33,6\% of students belong to a special medical group. We divided students, who have chronic diseases, according to the main diagnosis: cardiovascular system pathology (CVS) $-32 \%$, locomotor apparatus pathology- 28,6\%, eyesight pathology- $15,6 \%$, endocrine system pathology $-7,5 \%$, respiratory system pathology - 6,1\%, digestive apparatus pathology - 2,7\%, psychoneuropathic diseases $-2,7 \%$, hematopathy $2,7 \%$, gynaecological diseases $-1,4 \%$, skin pathology $-0,7 \%$. Low functional abilities of a cardiac muscle were stated among $60,8 \%$ of junior students, $1-2$ degree scoliosis among $77,9 \%$ of students, varicose veins of lower extremities among $70,4 \%$, vegetativevascular dystonia among $55,4 \%$ of students. special group included students with different chronic diseases. It demands physical culture and health improving lesson optimization, taking into consideration contra-indicated kinds of loads in case of all pathologies. Such kind of situation causes the necessity to choose adequate means and methods of physical upbringing. They have maximum health improving effects. They prevent negative influence on an organism of a person, who has chronic diseases. Some research workers offer to use dosed walking during the lessons with poor health state students $[1,2,3]$. Dosed walking normalizes peripheral circulation [4], provides correct posture formation [5], optimizes the state of central and vegetative nervous system and inner organs [6], provides fat burning [3]. It is recommended to organize the 
routs during dosed walking in picturesque places. It provides relaxing effect on psycho-emotional sphere $[7,8,9,10]$. During the attempt to realize the offered way of physical culture health improving lessons organization with students of special group we had two main difficulties: the 1st - higher educational establishment is situated in the center of the town, far away from picturesque places. The 2nd - the increasing negative attitude of young people to the formed physical culture traditions at higher educational establishments and their desire to form new stereotypes of motor activity. In this case we improved the methodology of dosed walking. We created "Historical Terrainkur" system. We laid the routes in a historical part of the town (Tver) concentrating them on the territory of former Tver Kremlin. Before the beginning of the terrainkur students are told about the influence of dosed walking on the functional state of an organism different systems. We explain the technique of correct walking. We give recommendations concerning movement along the stages. Students start from the building of a higher educational establishment following the teacher according to the definite route in a stated tempo. After the definite number of steps there was a stop near a historical object. During the stop students fulfill respiratory exercises and also listen to information about the history of the object within 1-2 minutes. The narration is illustrated by ancient images in the pictures, lithographies. One and the same route students overcome twice a week during two and more months. It depends on the training influence. At every lesson information about a historical object is added by new historical details. Students master the information about the history of an object, situated on the route. They move to a new historical route with new historical objects. There are no methodologies of dosed walking organization by means of "Historical Terrainkur". At the initial stage we had to create the criteria of the load dosing at such routs.

Table 1 - The parameters of dosed walking routs

\begin{tabular}{|c|c|c|c|c|}
\hline Load parameters & \multicolumn{4}{|c|}{ Routs (RT) } \\
\hline & RT-1 & RT-2 & RT-3 & RT-4 \\
\hline Length of the route (steps) & 1600 & 1800 & 2250 & 3000 \\
\hline Duration of the route (min) & 35 & 35 & 40 & 45 \\
\hline
\end{tabular}

The aim of the research: to create the criteria of the load dosing during physical culture and health improving lesson. It is organized by means of "Historical Terrainkur".

The objectives of the research:

1. To create the routs for dosed walking.

2. To organize physical culture lessons by means of "Historical Terrainkur" among the students of a special medical department.

3. To estimate the dynamics of students' functional state and health during terrainkur.

4. To state correlation dependence between students' functional state and the load parameters.

5. To compare the dynamics of students' health state at different routes.

\section{MATERIALS AND METHODS}

132 students of the Tver State Medical University 1st and the 2nd course took part in the research. All students belonged to a special health medical group (the average age $18 \pm 1$ ). We offered students to overcome 4 routs:

RT-1 - low intensity route - moderate speed of movement, short distance and duration of terrainkur, low density of the lesson;

RT-2 - the average intensity route - longer duration of the route and higher speed of walking than RT-1;

RT-3 - high intensity route- the average speed of movement, the average duration and length of the route, the average density of the lesson;

RT-4 - maximum intensity route - high speed of walking, length and duration of the route in comparison with RT-3, the average density of the lesson (table 1).

At all routs the density of the lesson corresponded with the demands of physical culture lesson organization with students of special medical group. 


\begin{tabular}{|c|c|c|c|c|}
\hline Duration of the load (min) & 20 & 20 & 25 & 30 \\
\hline Density of the lesson (\%) & 57 & 57 & 63 & 67 \\
\hline Orientative speed at the route (steps/min) & 85 & 90 & 90 & 100 \\
\hline The presence of climbing parts (abs.) & 1 & 1 & 3 & 3 \\
\hline
\end{tabular}

We offered students to move in quick tempo ("high tempo walking") following the teacher.

The object of the research: functional indices (pulse, pulse increase owing to the load, speed of moving at the stages of routs), students' health state, routs parameters of dosed walking.

At the beginning of the route, during the stop and at the end of the route we registered pulse (Ps) and the complaints. Students had complaints concerning their health state (HS), health state estimation (HE) and pulse estimation (PsE) according to 5-point scale [8], registered the time of movement between the stops (Tn), time of rest at stops (Tr), general time of the route (T). While moving students counted independently the number of steps between the stops (NSS), calculated the volume of movement speed $(\mathrm{V}=\mathrm{NSS} / \mathrm{Tn})$. We calculated the density of a lesson $\left(\mathrm{DL}=\mathrm{Tn} / \mathrm{T}^{*} 100\right)$.

Correlation connection between the load parameters (speed of movement, time of the load, number of the fulfilled steps), pulse reaction to the load and the dynamics of health state were determined according to Pearson coefficient (r), the validity was estimated according to confidence coefficient $(\mathrm{t} \geq 3$ "). The validity of differences between the average values of parameters was stated according to Student coefficient, confidence interval was $\mathrm{p}<0,05$.

Table 2 - Students' functional state dynamics during the routs $(\mathrm{M} \pm \mathrm{m})$

\begin{tabular}{|c|c|c|c|c|c|}
\hline \multirow{2}{*}{\multicolumn{2}{|c|}{ Index }} & \multicolumn{4}{|c|}{ Route (RT) } \\
\hline & & 1 & 2 & 3 & 4 \\
\hline \multicolumn{2}{|c|}{ The time of day } & 11.00 & 13.00 & 15.00 & 16.00 \\
\hline \multirow{2}{*}{ HE (points) } & initial & $3,6 \pm 0,2$ & $3,8 \pm 0,1$ & $3,1 \pm 0,3$ \# & $3,5 \pm 0,1 \#$ \\
\hline & control & $3,8 \pm 0,2$ & $4,12 \pm 0,08$ & $3,3 \pm 0,3$ \#\# & $3,6 \pm 0,1 \# \# \#$ \\
\hline \multirow{3}{*}{$\begin{array}{c}\text { Health state } \\
\text { dynamics (\% of } \\
\text { people) }\end{array}$} & improved & 31,3 & 40 & 23,5 & 17,9 \\
\hline & became worse & 6,2 & 11,7 & 11,8 & 10,3 \\
\hline & didn't change & 62,5 & 43,3 & 64,7 & 71,8 \\
\hline \multirow{2}{*}{$\begin{array}{l}\text { HS (\% of } \\
\text { people) }\end{array}$} & initial & 12,5 & 10 & $46,7^{*} \# \#$ & 15,4 \\
\hline & control & 6,2 & 6,7 & 17,6 & $10,3 \S$ \\
\hline \multicolumn{2}{|c|}{ Ps initial (beats/min) } & $98,1 \pm 4,4$ & $88,9 \pm 1,8^{*}$ & $93,2 \pm 3,8$ & $84,6 \pm 2,0^{* *} \S$ \\
\hline \multicolumn{2}{|c|}{$\Delta$ Ps in the middle of RT } & $31,7 \pm 2,2$ & $39,6 \pm 2,7^{*}$ & $48,1 \pm 5,4$ & $49,3 \pm 3,2^{* * *} \#$ \\
\hline
\end{tabular}

The received results are presented in tables 2, 3, 4. We stated the influence on the initial health state of students and its dynamics during terrainkur, when dosed walking was held. We stated the volume of the theoretical load, which was before it. Students complained of headache, hunger, stomachache, throat irritation, psycho-emotional tension. During "Historical Terrainkur" at all routs we revealed positive dynamics of students' health state. However we revealed its correlation with the load duration, time of the day and speed of movement at the stages. The lowest positive dynamics of students' health state was stated at maximum intensity route (RT-4). We stated the fact that $17,9 \%$ of students had health state improvement at the end of the route, $10,3 \%$ of the respondents started to complain of tiredness, body pain. By the end of high intensity route (RT-3) students were only very hungry (17,6\%). This route has the highest positive dynamics of complaints. However, according to health state estimation in points the dynamics is insignificant. Statistically valid dynamics of health state was registered at the average intensity route (RT-2). Considerable, but statistically not significant health state dynamics was stated at low intensity route (RT-1). 


\begin{tabular}{|c|c|c|c|c|}
\hline$\Delta$ Ps at the top of the load & $41,5 \pm 5,3$ & $52,2 \pm 2,5^{* * *}$ & $59,8 \pm 6,0^{* *}$ & $55,8 \pm 4,7^{*} \S \S \S$ \\
\hline$\Delta$ Ps at the end of RT & $15,1 \pm 4,4$ & $26,7 \pm 1,5^{*}$ & $24,9 \pm 5,0$ & $\begin{array}{c}38,3 \pm 3,7 \\
* * * \# \# \S\end{array}$ \\
\hline Time of RT (TRT) (min) & $30,4 \pm 0,15$ & $30,8 \pm 0,14$ & $\begin{array}{c}42,4 \pm 0,14 \\
* * * \# \# \#\end{array}$ & $\begin{array}{c}44,3 \pm 0,4 \\
* * * \# \# \S \S \S\end{array}$ \\
\hline Time of the load (TL) (min) & $19,1 \pm 0,5$ & $20,1 \pm 0,3$ & $\begin{array}{c}27,6 \pm 0,6 \\
* * * \# \# \#\end{array}$ & $\begin{array}{c}29,7 \pm 0,6 \\
* * * \# \# \# \S \S\end{array}$ \\
\hline Time of rest (min) & $11,3 \pm 0,4$ & $10,7 \pm 0,3$ & $\begin{array}{c}14,8 \pm 0,5 \\
* * * \# \# \#\end{array}$ & $\begin{array}{c}14,6 \pm 0,5 \\
* * * \# \# \#\end{array}$ \\
\hline Density of the lesson (DL) (\%) & $62,8 \pm 1,4$ & $65,4 \pm 1,0$ & $65,1 \pm 1,2$ & $67,0 \pm 1,1^{*}$ \\
\hline NSS general (abs.) & $1685 \pm 26,6$ & $\begin{array}{c}1859 \pm 10,9 \\
* * *\end{array}$ & $\begin{array}{c}2693 \pm 23,1 \\
* * * \# \# \#\end{array}$ & $\begin{array}{c}2883 \pm 40,5 \\
* * * \# \# \S \S \S\end{array}$ \\
\hline NSS average (abs.) & $337,0 \pm 5,3$ & $\begin{array}{c}309,0 \pm 2,2 \\
* * *\end{array}$ & $\begin{array}{c}385,0 \pm 3,3 \\
* * * \# \# \#\end{array}$ & $\begin{array}{c}360,0 \pm 5,1 \\
* * \# \# \# \S \S\end{array}$ \\
\hline Vav (steps/min) & $87,8 \pm 2,5$ & $\begin{array}{c}98,0 \pm 2,1 \\
* *\end{array}$ & $\begin{array}{c}99,9 \pm 1,9 \\
* * *\end{array}$ & $\begin{array}{c}106,0 \pm 3,3 \\
* * * \#\end{array}$ \\
\hline Vav (steps/hours) & $5318 \pm 160$ & $5641 \pm 114$ & $5902 \pm 130^{* *}$ & $5922 \pm 174^{*}$ \\
\hline
\end{tabular}

Note: * - The difference according to this index in terms of RT-1 is statistically valid $(\mathrm{p}<0,05)\left(* *-p<0,01,{ }^{* * *}-\right.$ $\mathrm{p}<0,001)$; \# - difference in terms of RT-2; § - difference in terms of RT-3

We revealed the following kinds of correlation:

strong direct - between speed and pulse increase by the end of the lesson, between the duration of the route and pulse increase because of the load, between the initial pulse and the dynamics of students' health state during dosed walking, between terrainkur duration and the number of complaints of poor health state at the end of the route, between the load intensity and pulse dynamics;

the average direct - between speed and pulse dynamics during the walking;

Table 3 - Indices correlation at the beginning and the end of the route (r)

\begin{tabular}{|c|c|c|c|c|c|c|c|c|c|c|}
\hline \multicolumn{2}{|c|}{ Index } & Ps init. & $\begin{array}{c}\text { PsE } \\
\text { init. }\end{array}$ & $\begin{array}{c}\Delta \text { Ps by } \\
\text { the end } \\
\text { of RT }\end{array}$ & V & $\begin{array}{c}\text { The } \\
\text { time of } \\
\text { day }\end{array}$ & T & Tn & DL & NSS \\
\hline \multirow{3}{*}{ HE } & init. & $-0,24$ & 0,5 & 0,25 & 0,039 & $-0,6$ & & & & \\
\cline { 2 - 13 } & contr. & 0,04 & 0,15 & $-0,05$ & $-0,2$ & $-0,55$ & $-0,8^{\prime \prime}$ & $-0,8^{\prime \prime}$ & 0,31 & $-0,68^{\prime \prime}$ \\
\cline { 2 - 13 } & $\Delta$ & $0,66^{\prime \prime}$ & $0,71^{\prime \prime}$ & $-0,71^{\prime \prime}$ & $-0,62$ & $-0,06$ & $-0,8^{\prime \prime}$ & $-0,74^{\prime \prime}$ & 0,51 & $-0,24$ \\
\hline \multirow{3}{*}{ HS } & init. & 0,26 & $-0,47$ & $-0,2$ & 0,01 & 0,58 & & & & \\
\cline { 2 - 12 } & contr. & $-0,05$ & 0,26 & $-0,01$ & 0,35 & $0,75^{*}$ & $0,72^{\prime \prime}$ & $0,71^{*}$ & $-0,25$ & 0,65 \\
\cline { 2 - 12 } & $\Delta$ & 0,4 & $-0,55$ & $-0,3$ & 0,0007 & 0,48 & 0,41 & 0,46 & 0,13 & 0,35 \\
\hline
\end{tabular}

During walking the dynamics of pulse depended on speed of movement (the average direct correlation) and on time of movement between the stages (weak inverse correlation). 
Table 4 - Indices correlation during the route (r)

\begin{tabular}{|c|c|c|c|c|}
\hline \multirow{2}{*}{ Index } & \multicolumn{4}{|c|}{ Load (walking at a given pace) } \\
\cline { 2 - 5 } & intensity & $\mathrm{V}$ & $\operatorname{Tn}(\mathrm{min})$ & NSS \\
\hline $\begin{array}{c}\text { Pulse increase } \\
\text { during the load }\end{array}$ & $0,97^{\prime \prime}$ & $0,63^{\prime \prime}$ & $-0,33$ & $-0,07$ \\
\hline
\end{tabular}

department. Vestnik Tomskogo gosudarstvennogo

During movement the indices dynamics of cardiovascular system functioning depended on speed of movement, pulse dynamics wasn't influenced by the time of movement and the number of the fulfilled steps.

\section{CONCLUSION}

The created routs for dosed walking have different influence on students' functional state (students with poor health state).

The load intensity on the route has a direct influence on pulse dynamics; positive dynamics of health state was registered during low and the average intensity loads.

We revealed the dependence of pulse dynamics on speed of movement and students' health state on the load duration and on speed of movement, on preceding theoretical load, on route length.

The greatest positive dynamics of students' functional state was stated on RT-2 (the average intensity route).

All students gave a positive estimation of physical culture lessons, organized by means of "Historical Terrainkur".

Thus, the load on the routes of "Historical Terrainkur" should be dosed according to the speed of movement, to general duration of the route. During the route selection we should take into consideration the level of the load at theoretical lessons. It preceded dosed walking.

\section{REFERENCES}

1. Vasilkovskaya Y.A., Malygina L.V., Tumasyan Y.A., Fedyakina L.K. The peculiarities of terrainkur and Nordic walking use in physical upbringing of students. Uchenye zapiski universiteta imeni P.F. Lesgafta. 2016: № 3(133); 47-49 [In Russ.].

2. Kryazhevskikh N.S., Kapilevich L.V. Terrainkurs use during physical upbringing lessons for the groups from remedial gymnastics universiteta. 2014: № 379; 181-183 [In Russ.].

3. Elgaytarov A.A., Elgaytarov L.P., Dzhaubaev Y.A., Petkov V.A., Romanov D.A. Kilometerslong walking as the means of students' health improvement and physical recreation. Vestnik AGU. 2016; 2(178); 147-154 [In Russ.].

4. Fukunaga T., Kawakami Y., Kubo K., et al. Muscle and tendon interaction during human movements. Exerc. Sports Sci. Rev. 2002; 30: 106110.

5. Zygman I.V. Nordic walking and terrainkurs as the form of special medical group students' physical health improvement at "Vitebsk State Medical University". Sovremennye metody formirovaniya zdorovogo obraza zhizni u studentov: sbornik nauchnyh statej [Modern methods of healthy life style formation among students: scientific articles collection]. Minsk: Center BGU publishing house. 2017: 179-183.

6. Fairclough S.J., Stratton G. 'Physical education makes you fit and healthy'. Physical education's contribution to young people's physical activity levels. Health Education Research. 2005; 20(1): 1423. DOI: 10.1093/her/cyg101.

7. Gobbi R.M., Davies I.G., Fairclough S.J., Mackintosh K.A., Warburton G.L., Stratton G., ..., Boddy L.M. Clustered cardiometabolic risk, cardiorespiratory fitness and physical activity in 1011 year old children. The CHANGE! Project baseline. Archives of Exercise in Health and Disease. 2012; 3: 207-213.

8. Hallal P.C., Andersen L.B., Bull F.C., Guthold R., Haskell W., Ekelund U. Global physical activity levels: Surveillance progress, pitfalls, and prospects. The Lancet. 2012; 380(9838): 247-257. DOI: 10.1016/So140-6736(12)60646-1.

9. Kristensen P.L., Korsholm L., Moller N.C., Wedderkopp N., Andersen L.B., Froberg K. Sources of variation in habitual physical activity of children and adolescent: The European youth heart study. 
Scandinavian Journal of Medicine and Science in Sports. 2008; 18(3): 298-308. DOI: 10.1111/j.16000838.2007.00668.x

10. McKenzie T.L., Sallis J.F., Kolody B., Faucette

F.N. Long term effects of a physical education curriculum and staff development program: SPARK. Research Quarterly for Exercise and Sport. 1997; 68(4): 280-291. DOI: 10.1080/02701367.1997.106 o8009.

Submitted: 19.04.2019

\section{Author's information:}

Elina V. Bulanova - Senior Lecturer, Tver State Medical University, 170042, Tver, Nikitina alley, House 8, Block 3, kv.10, e-mail: elina.bulanova@mail.ru

Mariya O. Kuzmina - Student, Tver State Medical University, 170042, Tver, Nikitina alley, House 8, Block 3, kv.10, e-mail: kuzminamaria2ooo@yandex.ru

Vladimir Sh. Kakaliya - Assistant, Tver State Medical University, 170042, Tver, Nikitina alley, House 8, Block 3, kv.10, e-mail: vladimirkakalia@mail.ru 